\title{
Sensory Neuron Subtypes Have Unique Substratum Preference and Receptor Expression before Target Innervation
}

\author{
Wei Guan, ${ }^{1}$ Manojkumar A. Puthenveedu, ${ }^{2}$ and Maureen L. Condic ${ }^{1}$ \\ ${ }^{1}$ Department of Neurobiology and Anatomy, University of Utah, School of Medicine, Salt Lake City, Utah 84132-3401, and ${ }^{2}$ Department of Biological \\ Sciences, Carnegie Mellon University, Pittsburgh, Pennsylvania 15213
}

\begin{abstract}
The factors controlling the specification and subsequent differentiation of sensory neurons are poorly understood. Data from embryological manipulations suggest that either sensory neuron fates are specified by the targets they encounter or sensory neurons are considerably more "plastic" with respect to specification than are neurons of the CNS. The prevailing view that sensory neurons are specified late in development is not consistent, however, with the directed outgrowth of sensory neurons to their targets and the characteristic spatial distribution of sensory neuron fates within the peripheral ganglia. To address when in development different classes of sensory neurons can first be distinguished, we investigated the interactions of early dorsal root ganglia neurons with the extracellular matrix before neurite outgrowth to targets. We found that subclasses of sensory neurons in early dorsal root ganglia show different patterns of neurite outgrowth and integrin expression that are predictive of their fates. In the absence of neurotrophins, presumptive proprioceptive neurons extend neurites robustly on both laminin and fibronectin, whereas presumptive cutaneous neurons show a strong preference for laminin. Cutaneous afferents that have innervated targets show a similar strong preference for laminin and show higher levels of integrin $\alpha 7 \beta 1$ than do proprioceptive neurons. Finally, presumptive proprioceptive neurons express fibronectin receptors, integrin $\alpha 3 \beta 1, \alpha 4 \beta 1$, and $\alpha 5 \beta 1$, at higher levels than do presumptive cutaneous neurons. Our results indicate that subtypes of sensory neurons have unique patterns of neurite outgrowth and receptor expression before target innervation.
\end{abstract}

Key words: dorsal root ganglia; neurotrophin; trk receptors; laminin; fibronectin; integrin

\section{Introduction}

Several lines of evidence indicate that developing sensory neurons of the dorsal root ganglia (DRGs) have unique identities after target innervation. DRG neurons have characteristic spatial organization; proprioceptive neurons are located predominantly in the ventral half of the ganglia, whereas cutaneous neurons are more broadly distributed along the dorsoventral axis, including the extreme dorsomedial quadrant (Henrique et al., 1995). Sensory neurons have characteristic patterns of gene expression (Hunt et al., 1992; Lawson, 1992) and are differentially sensitive to genetic deletion of neurotrophins or their high-affinity (trk) receptors (Reichardt and Farinas, 1997). DRG neurons path find to specific targets (Tosney and Landmesser, 1985b; Hollyday, 1990, 1995; Ferns and Hollyday, 1995; Hollyday and MorganCarr, 1995), and axons of neurons innervating the same targets are spatially associated in the peripheral nerve (Honig et al., 1998a). These data indicate that subpopulations of sensory neurons become distinct at some developmental stage but do not

\footnotetext{
Received Aug. 19, 2002; revised 0ct. 25, 2002; accepted Dec. 12, 2002.

This work was supported by National Institutes of Health Grant R01 NS38138 (M.L.C.). We thank Drs. S. A. Scott and H. J. Yost for critical reading of this manuscript, Dr. F. Lefcort for anti-trk antibodies, Dr. K. Zhang for advice on primer design, and A. Cooke for assistance with experiments. Antibodies were provided by the Developmental Studies Hybridoma Bank, developed under the auspices of the National Institute of Child Health and Human Development and maintained by The University of lowa, Department of Biological Sciences (lowa City, IA).

Correspondence should be addressed to Maureen L. Condic, Department of Neurobiology and Anatomy, University of Utah, School of Medicine, 20 North, 1900 East, Salt Lake City, Utah 84132-3401. E-mail: maureen.condic@hsc.utah.edu.

Copyright $\odot 2003$ Society for Neuroscience $\quad 0270-6474 / 03 / 231781-11 \$ 15.00 / 0$
}

reveal when subtypes can first be distinguished. Importantly, the current data do not distinguish between the two major possibilities; the fates of sensory neurons are determined by target interactions or are specified early in development by nontargetderived factors.

By analogy to central neuron specification (Tanabe and Jessell, 1996; Pfaff and Kintner, 1998; Edlund and Jessell, 1999), it is tempting to imagine that peripheral neurons are also determined early in development. However, it has not been possible to clearly demonstrate that sensory neurons have different patterns of gene expression (Anderson, 1999). The initial generation of different classes of sensory neurons depends on expression of neurogenin $1 / 2$ transcription factors, yet normal compliments of sensory neurons are generated in the absence of neurogenin function ( $\mathrm{Ma}$ et al., 1999). Similarly, the behavior of early sensory afferents does not clearly resolve when their fates are determined. "Naive" cutaneous and muscle afferents in vitro do not respond selectively to their appropriate targets (Adams and Scott, 1998), and, when challenged with an altered peripheral environment in vivo, sensory neurons make considerably more "mistakes" than do motor axons (Landmesser and Honig, 1986; Scott, 1988; Wang and Scott, 1997, 1999). These results suggest that sensory neuron fates are specified (or readily respecified) by the targets they encounter. In support of this view, ETS (erythroblastosis twenty-six oncogene)-domain transcription factors are expressed by all sensory neurons early in development and become restricted to neuronal subsets only after peripheral target innervation (Lin et al., 1998). However, this view is inadequate to explain the directed 
outgrowth of sensory neurons to their targets and the characteristic distribution of cell fates within the DRGs, both of which cannot be explained unless sensory neurons have identities before interacting with peripheral tissues.

To determine when in development different classes of sensory neurons can first be distinguished, we investigated whether early DRG neurons exhibit differing abilities to interact with the extracellular matrix (ECM). We demonstrate here that presumptive classes of sensory neurons show differences in trk and integrin expression, as well as differences in cell behavior that are predictive of their ultimate fates.

\section{Materials and Methods}

Ganglia culture and quantification of neurite outgrowth. White leghorn chicken lumbosacral DRGs at stage 23 and 30 (Hamburger and Hamilton, 1951) and sympathetic chain ganglia at stage 35 [embryonic day 9 (E9)] were dissected. Ganglia were cultured on UV-sterilized coverslips (Fischer Scientific, Houston, TX) that had been baked previously at $350^{\circ} \mathrm{C}$ for $12 \mathrm{hr}$ and then coated with either $50 \mu \mathrm{g} / \mathrm{ml}$ fibronectin (FN) or $20 \mu \mathrm{g} / \mathrm{ml}$ laminin (LM) (Invitrogen, Grand Island, NY) in PBS for $2 \mathrm{hr}$ at room temperature. Ganglia were cultured in F-12 medium supplemented with $10 \mathrm{ng} / \mathrm{ml} \mathrm{N} 2$ additives, $500 \mu \mathrm{M} \mathrm{L}$-glutamine, $25 \mu \mathrm{M}$ glutamic acid, $10 \mathrm{U} / \mathrm{ml}$ penicillin, $10 \mathrm{U} / \mathrm{ml}$ streptomycin (all from Invitrogen), and $10 \mathrm{ng} / \mathrm{ml}$ nerve growth factor (NGF) (R \& D Systems, Minneapolis, MN) or $10 \mathrm{ng} / \mathrm{ml}$ neurotrophin 3 (NT3) (Chemicon, Temecula, CA). In noneurotrophin (NoNT) cultures, NGF and NT3 were omitted. Culture dishes were incubated at $37^{\circ} \mathrm{C}$ in a humidified incubator with $5 \% \mathrm{CO}_{2}$.

Neurite outgrowth was scored blind by two observers at $24 \mathrm{hr}$ in live cultures and confirmed in fixed cultures that had been stained to label neurites (see below). Ganglia were scored as positive for outgrowth if any neurites extended at least one ganglion diameter beyond the limit of non-neuronal cells. Migration of non-neuronal cells away from the ganglia was similar for fibronectin and laminin substrata and not affected by the presence of neurotrophins (average distance from six experiments; 48 $\mu \mathrm{m}$ on laminin, $55 \mu \mathrm{m}$ on fibronectin). For some cultures without neurotrophins (see Fig. 7, Table 3), individual neurites whose growth cones were at least two cell diameters away from any non-neuronal cells were scored. Bundles of neurites were scored as single neurites. trk expression was assigned on the basis of double trkA/trkC immunolabeling (see below).

Retrograde labeling of cutaneous neurons. Cutaneous sensory neurons were labeled as described previously (LoPresti and Scott, 1994; Honig and Kueter, 1995). Briefly, chick embryos at stage 36 were dissected to expose the cutaneous femoralis lateralis and the cutaneous femoralis medialis nerves. Cutaneous neurites were labeled by pressure injection (Picospritzer) of $2.5 \mathrm{mg} / \mathrm{ml}$ DiI diluted in dimethylformamide into the nerve. Embryos were cultured overnight in HEPES-buffered, oxygenated $\mathrm{L} 15$ (Invitrogen) media at $37^{\circ} \mathrm{C}$, and then the first, second, and third lumbar DRGs were dissected. DRGs were dissociated ( $0.2 \%$ trypsin in PBS for $20 \mathrm{~min}$ at $37^{\circ} \mathrm{C}$ ), and the suspension was enriched for neurons by preplating on tissue culture plastic for $3 \mathrm{hr}$ and harvesting the nonadherent neuronal cells. The neurons were cultured on either laminin or fibronectin as described in the presence of both NGF and NT3. After 16 hr, cultures were fixed in $4 \%$ paraformaldehyde and stained with $4^{\prime}, 6^{\prime}$ diamidino-2-phenylindole. Cells with pyknotic nuclei were excluded from analysis. The percentage of labeled (cell body and proximal neurite) and unlabeled neurons that had extended neurites greater than one cell diameter on either substrate was determined blind by two observers at $40 \times$ magnification.

Immunohistochemistry of cultured DRGs. To stain axons, DRG cultures were fixed with $4 \%$ paraformaldehyde for $30 \mathrm{~min}$, rinsed with PBS, and blocked in PBS-normal goat serum (NGS) buffer: 5\% NGS, 0.1\% Triton $\mathrm{X}-100$, and $0.05 \%$ sodium azide for an additional $30 \mathrm{~min}$. Primary antibody 3A10 [anti-neurofilament-associated protein; Developmental Studies Hybridoma Bank (DSHB), Iowa City, IA] was applied at 1:200 dilution in PBS-NGS at $4^{\circ} \mathrm{C}$ overnight. On the next day, the cultures were rinsed with PBS-NGS, followed by FITC-conjugated secondary (Jackson ImmunoResearch, West Grove, PA) at 1:200 in PBS-NGS for $1 \mathrm{hr}$. Cov- erslips were rinsed with PBS and mounted in SlowFade (Molecular Probes, Eugene, OR).

Integrin staining in DRG cultures was performed as above, except that the DRG cultures were fixed in 2\% paraformaldehyde for $30 \mathrm{~min}$. DRGs were stained for integrin $\alpha 5$ [D71E2 (DSHB) and AB1928 (Chemicon)] and $\alpha 1$ and $\alpha 3$ (AB1934 and AB1920; Chemicon) and photographed using a $60 \times, 1.4$ numerical aperture oil objective. For trk staining in cultured DRGs, cultures were fixed in $4 \%$ paraformaldehyde for $30 \mathrm{~min}$, and double trkA/trkC staining was performed as indicated below for cryostat sections.

Immunohistochemistry of cryostat sections. Embryos were fixed in $4 \%$ paraformaldehyde for $4 \mathrm{hr}$ (stage 22) or overnight (stage 25-30). The embryos were transferred through 5, 15, and 30\% dextrose solutions, embedded in OCT (Sakura Finetek, Torrance, CA), and cryosectioned to a thickness of $16 \mu \mathrm{m}$. The sections were incubated for $20 \mathrm{~min}$ at room temperature in TBS buffer ( $10 \mathrm{~mm}$ Tris, $\mathrm{pH} 7.4$, and $150 \mathrm{~mm} \mathrm{NaCl}$ ) containing $0.1 \%$ Triton X-100. Rabbit polyclonal antibodies to trkA and trkC were generously provided by Dr. Frances Lefcort (Montana State University, Bozeman, MT). trkA/trkC double staining was conducted using tyramide signal amplification, according to the protocols of the manufacturer (NEN, Boston, MA). Goat anti-rabbit conjugated to biotin was used at 1:600, FITC-avidin at 1:600, and goat anti-rabbit conjugated to Cy-3 at 1:2000 (all from Jackson ImmunoResearch) in NGS buffer $(0.03 \mathrm{M}$ Tris, $0.15 \mathrm{M} \mathrm{NaCl}$, glycine at $10 \mathrm{mg} / \mathrm{ml}, 0.4 \%$ Triton X-100, and $10 \%$ normal goat serum). Primary antibodies against fibronectin (antibody B3/D6) and laminin (antibody 31; both from DSHB) were used at 1:1000 and 1:100 in NGS buffer. To stain motor and sensory neurons, sections were stained with BEN [anti-DM-GRASP (an immunoglobulinlike restricted axonal surface protein that is expressed in the dorsal funiculus and midline floor-plate cells of the chick spinal cord); DSHB] at 1:50 in NGS buffer. Photographs were taken on an Olympus Optical (Melville, NY) confocal microscope.

In situ hybridization. Stage 23 and 30 embryos were dissected in DEPC-PBS (PBS with $0.1 \%$ diethylpyrocarbonate, $\mathrm{pH} 7.1$ ) and fixed in $4 \%$ paraformaldehyde for $2 \mathrm{hr}$ at room temperature. Embryos were then prepared for sectioning by cryoprotecting the embryos through 5, 15, and $30 \%$ dextrose in DEPC-PBS for at least $2 \mathrm{hr}$ at room temperature and cryosectioned to a thickness of $16 \mu \mathrm{m}$ as described above. The integrin $\alpha 4, \alpha 6$, and $\alpha 7$ digoxigenin (DIG)-labeled RNA probes were synthesized by following protocol of the manufacturer (Roche Products, Hertforshire, UK). For $\alpha 4$, a 624 bp probe encoding the N-terminal 119-743 nucleotides and a $599 \mathrm{bp}$ fragment corresponding to the C-terminal $3058-3656$ nucleotides gave identical results. For $\alpha 6$, a 642 bp RNA probe encoding N-terminal 187-829 nucleotides and a 596 bp C-terminal probe (from nucleotides 2521-3116) gave identical results. For $\alpha 7$, a 325 bp RNA probe encoding N-terminal 8-332 nucleotides and a 397 bp C-terminal probe (from nucleotides 95-491) gave identical results.

The in situ hybridization was performed as described by Henrique et al. (1995) with some modification. Briefly, the section slides were refixed with $4 \%$ paraformaldehyde in DEPC-PBS for $10 \mathrm{~min}$. Then the slides were washed twice with DEPC-PBS and acetylated by immersing them in fresh acetylation medium $(1.3 \%$ triethanolamine, $0.06 \% \mathrm{HCl}$, and $0.25 \%$ acetic anhydride in DEPC $-\mathrm{H}_{2} \mathrm{O}$ ) for $10 \mathrm{~min}$. After permeabilizing the sections with PBST (1\% Tween 20 in DEPC-PBS) for 30 min, hybridization with $1 \mu \mathrm{g} / \mathrm{ml}$ DIG-labeled RNA probes was performed overnight under stringent conditions ( $5 \times$ DEPC-SSC and 50\% formamide at $\left.60^{\circ} \mathrm{C}, \mathrm{pH} 7\right)$. On the next day, the section slides were washed extensively with $2 \times$ SSC and $0.2 \times$ SSC at $60^{\circ} \mathrm{C}$ for at least $1 \mathrm{hr}$ and then incubated in 1:2000 alkaline phosphatase-coupled anti-DIG antibody in buffer B1 ( $100 \mathrm{~mm}$ Tris $\mathrm{HCl}, \mathrm{pH} 7.5$, and $150 \mathrm{~mm} \mathrm{NaCl}$ ) at room temperature for 3 $\mathrm{hr}$. Then the section slides were washed with fresh NTM buffer $(100 \mathrm{mM}$ $\mathrm{NaCl}, 100 \mathrm{~mm}$ Tris $\mathrm{HCl}, \mathrm{pH} 9.5$, and $50 \mathrm{~mm} \mathrm{MgCl}_{2}$ ) and were stained with 4-nitro blue tetrazolium chloride/x-phosphate/5-bromo-4-chloro-3indolyl-phosphate (Roche Products) for overnight at room temperature in dark. After color development, the section slides were washed with DEPC $-\mathrm{H}_{2} \mathrm{O}$ and mounted as described above. For all experiments, control sense probes were negative.

Reverse transcription-PCR analysis. Stage 23 and stage 30 chick DRGs 
Table 1. Summary of PCR primers

\begin{tabular}{lll}
\hline Gene & Sense primer & Antisense primer \\
\hline NGF & 5'GGACCAAGAGGACTGCACAT & 5'TtCCTGCTGAGCACACACA \\
NT3 & 5'TCTTCGTGGCATTCAGTCAA & 5'GGAGTTCCAGTGCTTGTCGT \\
$\alpha 1$ & 5'CAGTGGTGATGACACAGAAGAC & 5'AACTTCTCCAGCCTGAGCTGT \\
$\alpha 3$ & 5'ACAGCACCCCGCAACCTTCCG & 5'AAGAAGGCCGCCCGGTCGTGC \\
$\alpha 4$ & 5'TTGCTTTTCCAAAGCCTCAT & 5'GTGGTGCACTCCTTCCAGAT \\
$\alpha 5$ & 5'GGTTTGGTGTACATCTACAGCGG & 5'GCGAAGCGAGTGGCAGCACGGG \\
$\alpha 6$ & 5'ATTTTGGAGTAACATCGTTGG & 5'ACGCATCAGAAGTAAGCCTCTC \\
$\alpha 7$ & 5'GTCCTGGCACTGCTGATCTT & 5'GTCCCACTGCAAGCAATCTT \\
GAPDH & 5'AGTCGGAGTCAACGGATTTG & 5'TCTCCATGGTGGTGAAGACA \\
\hline
\end{tabular}

were cultured $24 \mathrm{hr}$ on non-adherent, bovine serum albumin-coated dishes in either the presence or absence of neurotrophins. mRNA was extracted using Oligotex Direct (Qiagen, Hilden, Germany) and reverse transcripted into cDNA using Superscript First-Strand Synthesis kit (Invitrogen). Control primer sequences were designed to amplify a $500 \mathrm{bp}$ product of chicken glyceraldehyde-3-phosphate dehydrogenase (GAPDH) (Dugaiczyk et al., 1983). Specific primers were designed on the basis of chicken NGF (Meier et al., 1986), NT3 (Maisonpierre et al., 1992), integrin $\alpha 1$ (Obata et al., 1997), integrin $\alpha 3$ (Hynes et al., 1989), integrin $\alpha 4$ (Kil et al., 1998), integrin $\alpha 6$ (de Curtis, 1991), and integrin $\alpha 7$ (GenBank accession number BI066921) sequences. Primers for chicken $\alpha 5$ were designed by aligning the Homo sapiens and Mus musculus sequences with BLAST and choosing areas that were unique to integrin $\alpha 5$. Sequencing of the PCR product confirmed highest identity (66\%) with human integrin $\alpha 5$ and non-identity with other chick $\alpha$ integrins (GenBank accession number AY029523) (Table 1).

The linear range for PCR amplifications was determined by varying the cycle number for all primer combinations and using conditions in which the amplified product increased linearly as a function of cycle number (usually between 32 and 35 cycles at $94^{\circ} \mathrm{C}$ ). PCR products were visualized on $2.5 \%$ agarose gels stained with ethidium bromide and confirmed by sequencing. Relative abundance of the PCR products was measured from digitized images of the stained gel using Geldoc software (Bio-Rad, Hercules, CA). Measured intensities were normalized to the internal control GAPDH band and expressed relative to the NoNT or E7 condition.

\section{Results}

\section{Early development of chick sensory ganglia}

Sensory neurons in chick have characteristic spatial distribution and are born over a relatively long period of embryonic time. At stage 23-24, many of the neurons in the dorsomedial quadrant of the DRG are still dividing (Lawson et al., 1974; Carr and Simpson, 1978; Lawson and Biscoe, 1979; Rifkin et al., 2000), whereas as early as stage 19-20 in the hindlimb region, neurons in the ventrolateral quadrant of lumbosacral DRG are extending axons toward their targets (Fig. 1) (Tosney and Landmesser, 1985a; Hollyday, 1995; Wang and Scott, 2000). Ventrolateral cells are a mixed population, containing almost all proprioceptive and some cutaneous afferents (Honig, 1982; Oakley et al., 2000). At early stages, the majority of ventrolateral DRG cells express trkC and/or trkB (Fig. 2) (Rifkin et al., 2000). The spatial localization of trkC-expressing cells to the ventrolateral DRG is not as pronounced in rodents (Mu et al., 1993), but a very similar pattern is observed in human DRGs (Shelton et al., 1995).

By stage 30, the axons of early extending ventrolateral neurons have already reached their targets and are dependent on neurotrophins for survival, whereas the latest arising dorsomedial neurons have not yet extended axons and are still neurotrophin independent (Fig. 1). Very few (if any) ventrolateral cells are born at stage 30 (Carr and Simpson, 1978), and very few (if any) of the dorsomedial cells being generated at this stage are fated to be

\section{Stage 24}
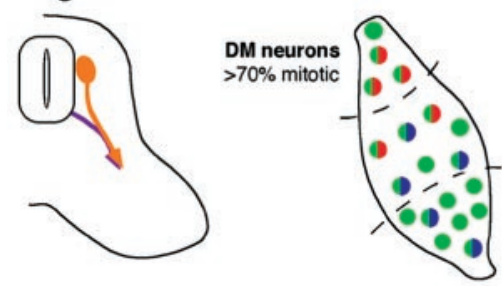

T trkA and trkC

trkB and trkC

- trkC only

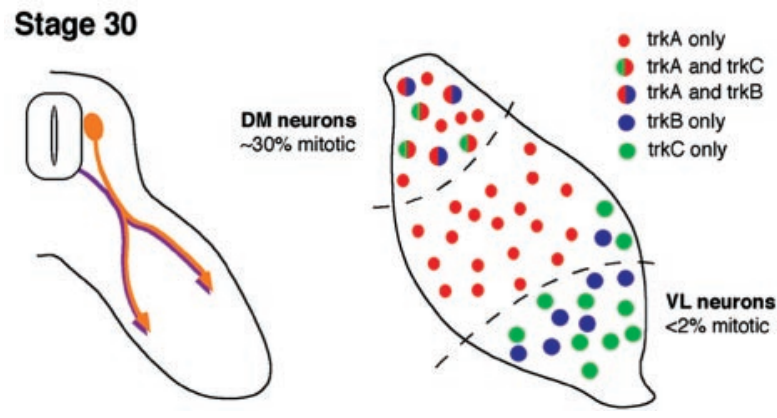

Figure 1. A schematic diagram of DRG development at stages $23-24$ and 30 . Diagram summarizes sensory axon extension from the whole DRG (left) (Tosney and Landmesser, 1985a; Hollyday, 1995; Wang and Scott, 2000) and the patterns of mitosis (Carr and Simpson, 1978) and trk expression (Rifkin et al., 2000) in dorsomedial (DM) and ventrolateral (VL) thirds of the DRG (right). At stage 23-24, the neurons are still being born throughout the DRG, although the earliest born ventrolateral neurons have begun extending axons. These early cells are trkC+ and include most proprioceptive neurons as well as cutaneous neurons. By stage 30 , ventrolateral cells have exited the cell cycle, and most axons from cells in this region have innervated targets and are neurotrophin dependent. In contrast, the latest born dorsomedial cells are still being generated. Newly born neurons that have not yet extended axons into the periphery are neurotrophin independent. All dorsomedial cells are fated to be cutaneous afferents.

proprioceptive (Honig, 1982; Scott, 1990). Thus, late arising neurons are primarily cutaneous, whereas early populations contain a mix of sensory subtypes that includes most proprioceptive neurons.

\section{Sensory neuron subtypes initially extend axons in different environments}

We examined the expression of neurotrophin receptors in early sensory ganglia and the environment through which the earliest arising sensory axons extend. In agreement with the work by Rifkin et al. (2000), we observed that the earliest arising sensory axons in the hindlimb (stage 22) express exclusively trkC, the high-affinity NT3 receptor (Fig. 2E). These early arising axons extend ventrally from the DRG through the extracellular matrix to contact the motor axons of the ventral root. At stage 22, fibronectin was expressed at high levels along the pathways of trkC-expressing axons (Fig. $2 \mathrm{~A}$, arrowheads). Laminin was found in the basement membranes of the neural tube, the notochord, the skin, and the dermamyotome but was primarily absent from the pathway of early extending sensory neurons (Fig. $2 \mathrm{~B}, \mathrm{C}$ ). At stage 22, trkA was expressed in a few DRG neurons (Fig. $2 D$ ), but these neurons have not yet extended axons, and most express both trkA and trkC (Fig. 2 F). By stage 25, numerous trkA- and trkC-expressing axons have extended into the limb to innervate targets (Fig. 2G,H). As described in DRGs of both chicks (Rifkin et al., 2000) and humans (Shelton et al., 1995), trkA+ and trkC+ populations are primarily nonoverlapping at this stage (Fig. 2I). In contrast to earlier stages, growth cones were not observed in the ECM surrounding the nerve at stage 25, indicating that axons arising from the DRG at this stage extend along pre- 
existing axons for the initial segment of their route to the periphery. These results suggest that there may be differences in the ability of early and late arising axons with different presumptive fates to interact with ECM proteins, particularly fibronectin.

\section{NGF- and NT3-responsive neurons show different outgrowth on LM and FN}

In these and subsequent experiments (Fig. 3) (see Figs. 5, 7, 8), we elected to culture intact DRGs because dissociated DRG neurons appear to lose many subtype characteristics, with most cells expressing multiple trk receptors (Gallo et al., 1997; Shepherd et al., 1997; Tuttle and O'Leary, 1998). Cultured, intact DRGs retain a more characteristic pattern of trk expression (F. Lefcort, personal communication; M. L. Condic, unpublished observation) and are therefore likely to be a better model for studies of cell determination in DRG neurons.

To investigate whether there were consistent differences in cell behavior between different classes of sensory neurons, DRGs from stage 30 chick embryos were cultured on LMor FN-coated coverslips in the presence of either NGF or NT3. At stage 30, most DRG neurons have extended to the periphery, and neurotrophin dependency approximately reflects sensory modality. We determined the number of DRGs that extended neurites long enough to pass beyond the limit of nonneuronal cells present in the cultures (see Materials and Methods). NT3-responsive neurons extended neurites equally well on either LM or FN (Fig. 3A,B). In contrast, NGF-responsive neurites grew significantly better on LM compared with FN (Fig. 3C,D). These results indicate that there are pronounced differences in substrate preference between NGF- and NT3-responsive sensory neurons of stage 30 embryos.

\section{Labeled cutaneous neurons also show a strong preference for laminin substrata}

To investigate whether the strong preference for LM that we observed in cultured NGF-responsive neurons (most should be cutaneous) was also a property of cutaneous neurons that had innervated targets, we examined the outgrowth of retrogradely labeled cutaneous neurons and unlabeled neurons (mixed phenotypes of neurons) in culture. Cutaneous neurons from stage 36 embryos were retrogradely labeled from cutaneous nerve (see Materials and Methods), and, after overnight culture of embryos to allow labeling of cell bodies, the DRGs were removed and dissociated and neurons were placed in culture. Neurons were cultured in the presence of both NGF and NT3 to ensure that the majority of neurons would survive in culture. In dissociated culture, most DRG neurons express multiple trks (Gallo et al., 1997; Shepherd et al., 1997; Tuttle and O'Leary, 1998), should respond to both NGF and NT3, and should therefore respond to both neurotrophins. Labeled cutaneous neurons extended neurites much more frequently on LM than on FN (Fig. 4). These results indicate that, similar to NGF-selected sensory neurons, real cu-
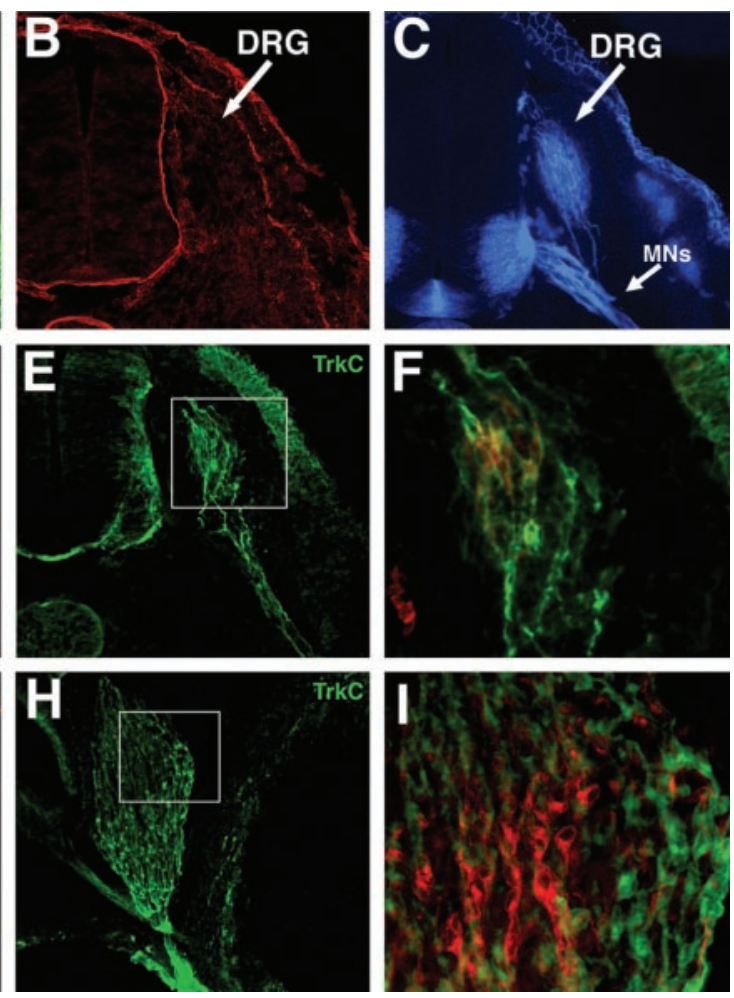

Figure 2. Sensory neurons expressing trkC arise earlier in development than trkA-expressing neurons and extend axons stage 22, laminin was expressed mainly in the basement membranes of the neural tube (NT), the notochord (NC), the skin, ( bundles in the ventral aspect of the DRG. $H$, trkC continues to be expressed in ventrolateral neurons. I, Enlargement of boxed areas in $G$ and $H$. trkA and trkC expression overlaid. Most trkA+ neurons do not express trkC at stage 25.
FN
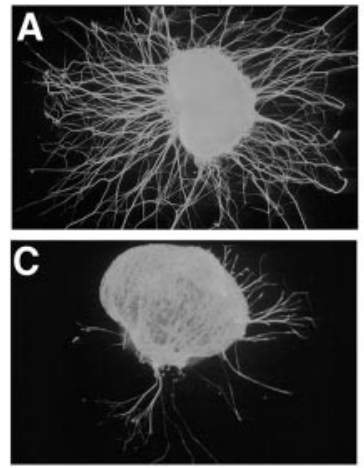
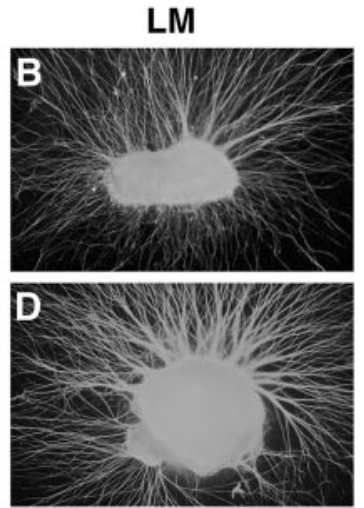

NT3

NGF
Figure 3. NGF-and NT3-responsive neurons show different neurite outgrowth on LM and FN substrata. DRGs from embryonic day 7 (approximately stage 30 ) were cultured $24 \mathrm{hr}$ in the presence of NT3 $(A, B)$ or NGF $(C, D)$ on fibronectin $(A, C)$ or laminin $(B, D)$. $A$, NT3-responsive neurons extend neurites robustly on FN substrata. $B$, NT3-responsive neurons also extend neurites robustly on LM. C, In contrast to NT3-responsive neurons, NGF-responsive neurons are much less likely to extend neurites on FN. D, Extension of NGF-responsive neurites was robust on laminin. Data from at least nine independent experiments were examined. Number of DRGs extending axons and the total number examined in each condition are as follows: NT3-FN, 23 of 32 (72\%); NT3-LM, 27 of 30 (90\%); NGF-FN, 9 of 27 (33\%); and NGF-LM, 29 of 29 (100\%). Number of DRGs extending neurites in the NGF-FN condition is significantly different from all other conditions ( $p<0.005$; Fisher's exact test). 


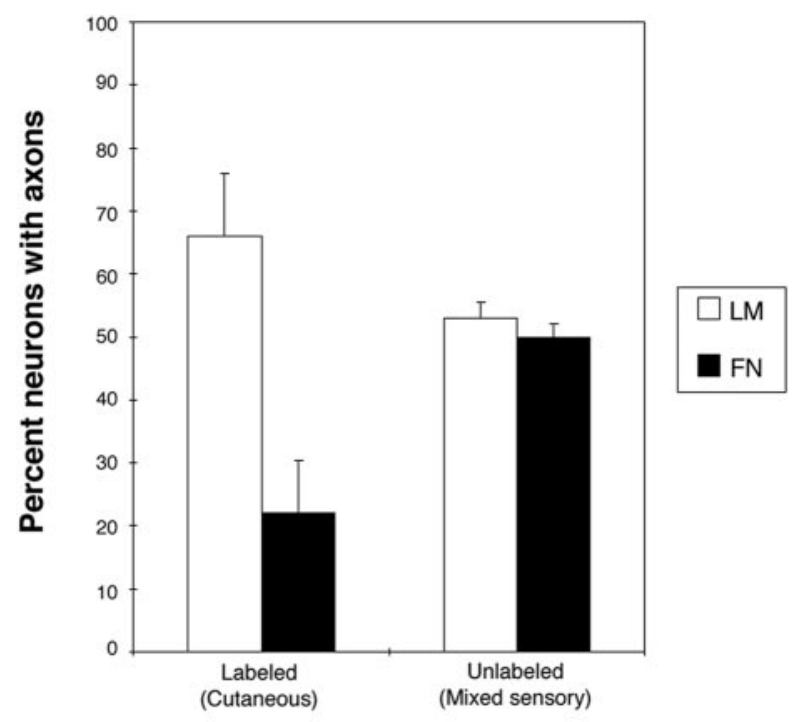

Cell type

Figure 4. Retrogradely labeled cutaneous neurons that have innervated targets also show a strong preference for laminin. Quantification of neurite extension from labeled and unlabeled neurons. Unlabeled cells (mixed sensory modalities, including cutaneous) extend equally well on LM and FN substrata. Labeled, cutaneous neurons are three times as likely to extend on LM as on FN. Results from three experiments are presented. Numbers of cells counted are as follows: labeled on LM, 207; labeled on FN, 303; unlabeled on LM, 102; and unlabeled on FN, 102. Percentage of labeled neurons extending on $\mathrm{LM}$ and $\mathrm{FN}$ are statistically different from each other and from control (unlabeled) neurons ( $p<0.001 ; \chi^{2}$ test).

taneous neurons that had innervated their targets in vivo also have a strong preference for LM.

\section{Substratum preferences persist in the absence of added neurotrophins}

To determine whether the substrata preferences that we observed reflected differences in the inherent properties of subclasses of sensory neurons or properties induced by target-derived neurotrophins, we tested neurite outgrowth of sensory neurons that had not yet been exposed to targets. Several lines of evidence suggest that neurites at the earliest developmental stages (i.e., neurites that have not yet reached targets) are neurotrophin independent (Davies, 1994, 1998). Culture in the absence of exogenous neurotrophins at successively later developmental stages should reveal the properties of a progressively restricted pool of neurotrophin-independent neurons that are undergoing axonogenesis for the first time and have therefore not been exposed to target-derived factors, including neurotrophins (Fig. 5A). Indeed, DRGs from stage 36 cultured without neurotrophins do not extend axons on either LM or FN (data from three experiments; data not shown), indicating that regenerating, neurotrophin-dependent neurons do not extend axons in our cultures without trophic support.

In agreement with published studies in rodents (Farinas et al., 1996; White et al., 1996), PCR analysis of chicken DRGs from stage 23 and 30 indicated that NGF message was not detectable in DRGs at either stage examined, whereas low levels of NT3 message are present only at stage 30 (data not shown). Therefore, although culture in the absence of neurotrophins biases in favor of neurons that have not been exposed to target-derived factors, including neurotrophins, it does not exclude a role for DRG-associated NT3 in the behavior of very late arising neurons.
FN
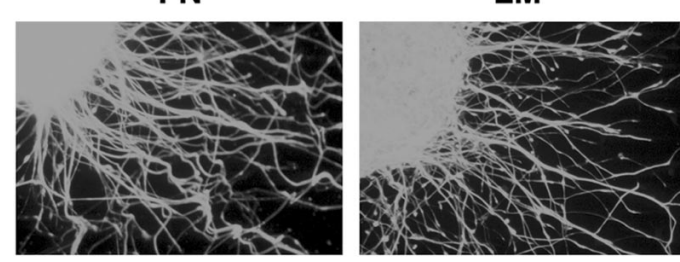

Stg 23

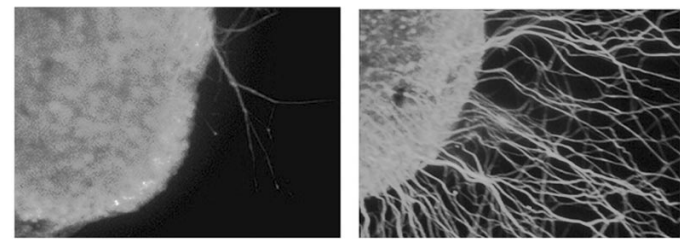

$\operatorname{Stg} 30$

Figure 5. Substratum preferences persist in the absence of exogenous neurotrophins. DRGs from stage 23 and stage 30 embryos are cultured $24 \mathrm{hr}$ in the absence of neurotrophins on either fibronectin or laminin. At stage 23 (E3.5-E4), the majority of the neurites extending are trkC+ (see Figs. 1, 2, 7, Table 3) and fated to be proprioceptive. At this stage, neurites grew robustly on both LM and FN in the absence of neurotrophins. At stage 30 (E6.5), most neurons undergoing initial axonogenesis are fated to be cutaneous. None of the DRGs cultured on FN at this age extended neurites long enough to pass through the limit of non-neuronal cells (see Materials and Methods). In contrast, DRGs cultured on LM robustly extended neurites in the absence of neurotrophins at stage 30 . For all conditions, at least three independent experiments were examined. Number of DRGs extending axons out of the total number examined in each condition are as follows: stage $23-\mathrm{FN}, 10$ of 12 (83\%); stage $23-\mathrm{LM}, 9$ of $10(90 \%)$; stage $30-\mathrm{FN}, 0$ of $25(0 \%)$; and stage 30 -LM, 20 of 26 (77\%). Number of DRGs extending axons on fibronectin at stage 30 is significantly different from all other conditions ( $p<0.001$; Fisher's exact test).

In chicks, culture at stage 23 in the absence of exogenous neurotrophins will select for the earliest arising neurons that have not yet become dependent on neurotrophins, a population that should include the majority of presumptive proprioceptive afferents (Fig. 1). In contrast, culture at stage 30 in the absence of exogenous neurotrophins should exclude the majority of proprioceptive afferents and enrich for late-arising cells (Fig. 1) that are primarily fated to be cutaneous (Scott, 1990).

At stage 23, neurotrophin-independent neurites (a population enriched for presumptive proprioceptive neurites) grew robustly on both LM and FN in the absence of bath-applied neurotrophins (Fig. 5). In contrast, neurites extending from stage 30 DRGs in the absence of exogenous neurotrophins (a population enriched for presumptive cutaneous neurons) were essentially incapable of growing on FN (Fig. 5). These results suggest that, before target innervation, presumptive cutaneous and proprioceptive DRG neurons have inherent differences in substratum preference that do not appear to be induced by factors outside of the DRG itself, including target-derived neurotrophins. DRGassociated NT3 could play a role in the outgrowth of very late arising neurons, yet it would have to induce behavior opposite that observed in most NT3-responsive neurons (Fig. 3). Importantly, any transient or low-level expression of neurotrophins by the DRG does not alter the observation that differences in outgrowth are observed before target innervation and therefore independent of target-derived factors.

\section{Sympathetic neurons prefer laminin, regardless of neurotrophin treatment}

To investigate whether the substratum preferences that we observed were restricted to cutaneous DRG neurons or whether they were a general property of NGF-responsive neurons, we examined the ability of sympathetic neurons to extend on laminin and fibronectin. Sympathetic ganglia contain only a single type of neuron. Stage 36 sympathetic neurons of chick embryos 
express both trkA and trkC (Dechant et al., 1993; Kahane and Kalcheim, 1994; Hallbook et al., 1995; Backstrom et al., 1996; Ockel et al., 1996; Holst et al., 1997) and can be maintained by either NGF or NT3 in culture (Dechant et al., 1993). At later embryonic stages, sympathetic neurons are dependent on NGF for survival (Levi-Montalcini, 1987). Examining the properties of sympathetic neurons in culture allowed us to both determine whether growth on laminin was a general property of trkAexpressing neurons and better analyze the role of neurotrophins in substratum preference in a homogeneous cell population.

Sympathetic ganglia were cultured in the presence of NGF or NT3 or in the absence of added neurotrophins. Similar to cutaneous DRG neurons, sympathetic neurons showed a strong preference for laminin substrata, regardless of the presence or absence of neurotrophins in the media (Fig. 6, Table 2). Moreover, sympathetic neurons did not extend neurites on fibronectin in the presence of NT3 (Table 2), suggesting that NT3 does not induce growth on fibronectin. The failure of sympathetic neurons to extend neurites was specific for fibronectin substrata (i.e., it did not reflect a loss of ability to extend neurites), because ganglia cultured $24 \mathrm{hr}$ on fibronectin (Fig. 6 B; no neurite extension) robustly extended neurites when subsequently transferred to laminin substrata (Fig. 6C). These results suggest that preferential neurite extension on laminin is an intrinsic property of the cutaneous DRG and sympathetic neurons.

\section{Substratum preferences are not strictly predicted by trk expression}

To better characterize the identities of DRG neurons extending neurites at stage 23 and stage 30 in the absence of bath-applied neurotrophins, we examined the patterns of trk expression for DRGs cultured on laminin and fibronectin without neurotrophin treatment. After $24 \mathrm{hr}$ in culture, DRGs were double stained for trkA and trkC. In agreement with the results from double-trk staining on sections (Fig. 2), most neurites in culture at stage 23 expressed only trkC (Fig. 7B, D, Table 3). Extension on LM and FN was approximately equal for trkC-expressing neurites at stage 23 (Table 3), supporting the results that NT3-responsive neurons grow robustly on both molecules (Fig. $3 A, B$ ). As predicted, very few neurites expressed trkA at this stage (Fig. $7 A, C$ ), and nearly all of these neurites coexpressed trkC (Rifkin et al., 2000). However, even among the small number of trkA + neurites observed, there was a significant ( $p<0.05$; $t$ test) preference for laminin substrata (Table 3), which is consistent with the superior neurite outgrowth of NGF-responsive neurons cultured on LM (Fig. $3 C, D)$.

At stage 30, fewer neurites extended overall (1600 at stage 30 vs 2339 at stage 23), but a higher percentage of neurites expressed trkA (Fig. 7 E, G, Table 3), consistent with the increased numbers of trkA + cells observed in vivo (Fig. 2) (Rifkin et al., 2000). In contrast to the observations in vivo in which only $9 \%$ of cells coexpress trkA and trkC at this stage (Rifkin et al., 2000), all neurotrophin-independent axons observed expressing trkA in stage 30 cultures also expressed trkC (Table 3 ). This result suggests that either trk expression in cultured DRGs is more plastic than it is in vivo or neurons coexpressing trkA and trkC are highly enriched in the neurotrophin-independent population at this stage. Surprisingly, all neurotrophin-independent neurons in older cultures preferred laminin, i.e., both trkA + neurites and trkC + neurites at stage 30 preferentially extended on LM, although this preference was stronger for trkA+ neurites (Table 3). Neurotrophin-independent neurons extending axons at this stage are predominantly fated to be cutaneous, and this result is
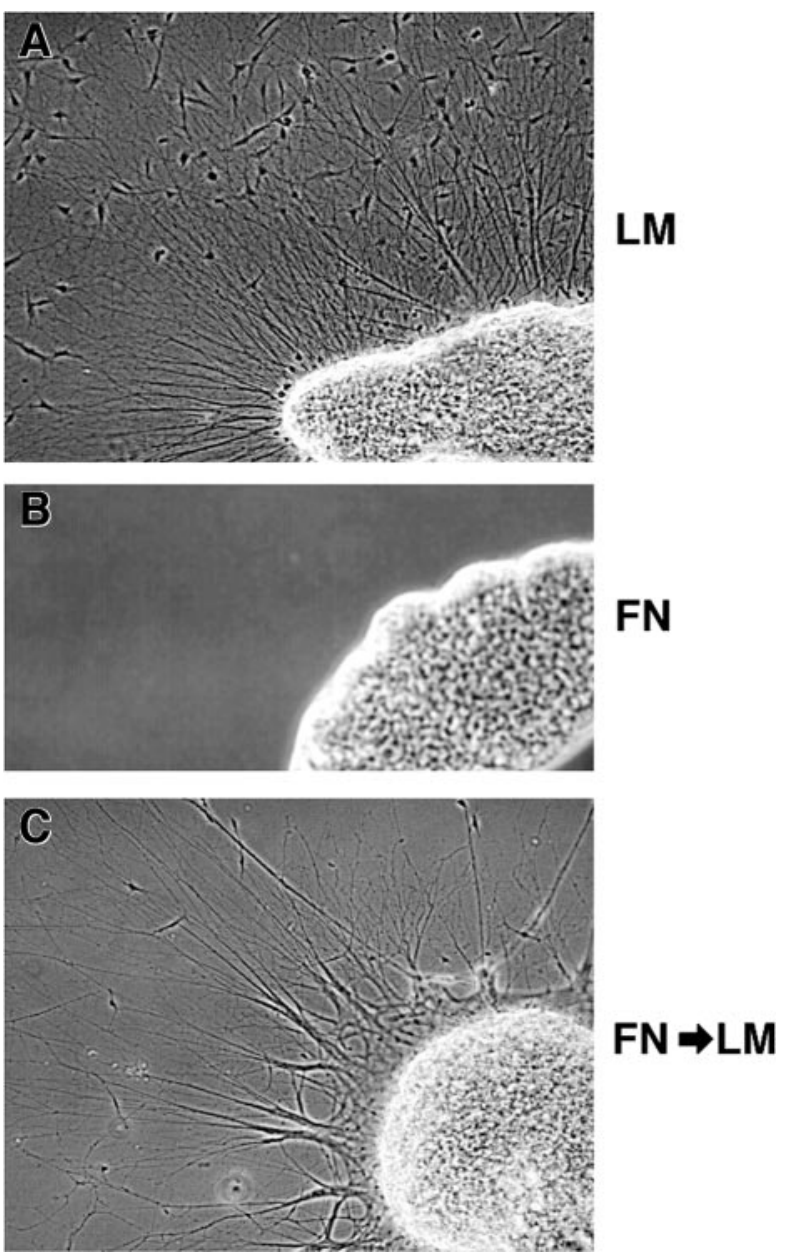

Figure 6. Sympathetic neurites extend preferentially on laminin. Lumbosacral sympathetic chain ganglia were dissected from stage $35 / 36$ (E9) embryos and cultured on either laminin $(A)$ or fibronectin $(B)$ for $24 \mathrm{hr}$. Neurites extended only on laminin, regardless of neurotrophin treatment at the time of culture (Table 2). C, Failure to extend on fibronectin did not reflect loss of ability to extend axons; ganglia removed from fibronectin substrata after the initial $24 \mathrm{hr}$, transferred to laminin substrata, and cultured for an additional $24 \mathrm{hr}$ extended axons robustly.

Table 2. Sympathetic neurons preferentially extend on laminin, independent of neurotrophins

\begin{tabular}{lllllll}
\hline & NGF/LM & NT3/LM & NoNT/LM & NGF/FN & NT3/FN & NoNT/FN* \\
\hline $\begin{array}{l}\text { \% Ganglia } \\
\text { extending } \\
\text { neurites }(n)\end{array}$ & $100 \%(15)$ & $85 \%(13)$ & $71 \%(14)$ & $13 \%(15)$ & $15 \%(13)$ & $0 \%(8)$ \\
\hline
\end{tabular}

Sympathetic ganglia from stage 35/36 (E9) embryos were cultured $24 \mathrm{hr}$ in the presence of the indicated neurotrophins or without neurotrophins (NoNT). Percentage of ganglia extending neurites beyond the limit of the nonneuronal cells was determined as for Figures 3 and 5 .

*Indicates that fewer ganglia attached to fibronectin substrata in the absence of exogenous neurotrophins, reducing the total number analyzed. Unattached ganglia were able to extend axons when replated on laminin substrata (Fig. 60). Data from four independent experiments are given.

consistent with the preference for laminin exhibited by cutaneous neurons (Figs. 3-5). These results further suggest that trkA expression is not a reliable predictor of neuronal phenotype and growth on specific matrix proteins.

\section{Different classes of sensory neurons express different integrins}

Differences in neurite outgrowth on extracellular matrix proteins are likely to reflect differences in the expression of integrins, the primary receptors mediating neuronal outgrowth on matrix pro- 


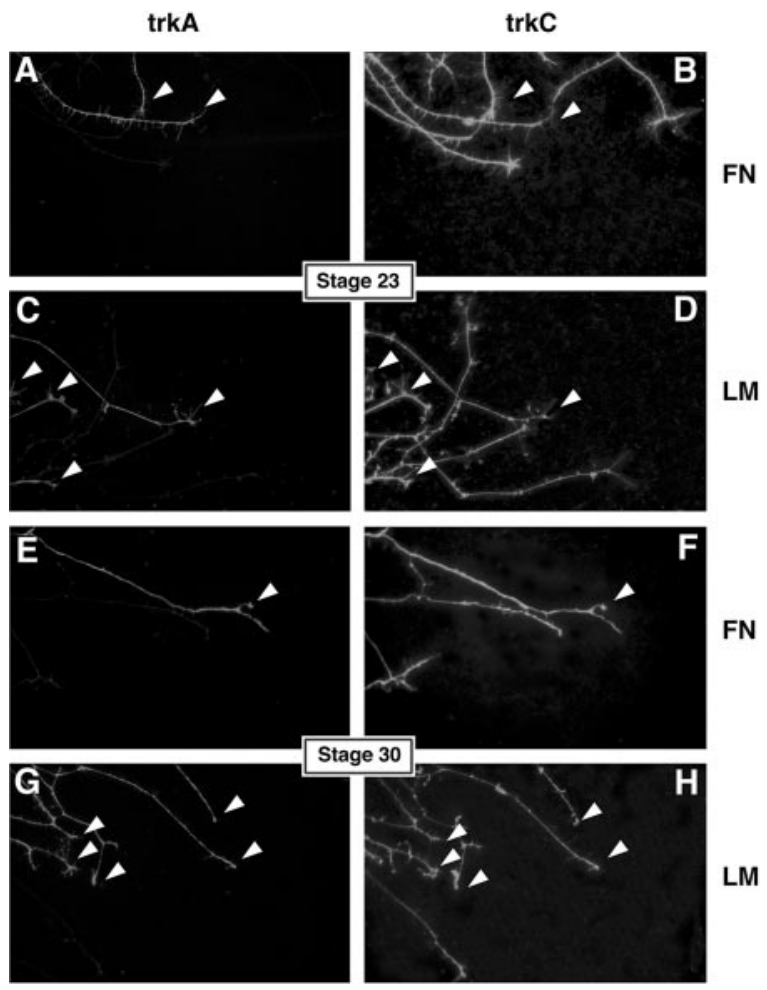

Figure 7. trkA + neurites from stage 23 and all neurites from stage 30 prefer laminin. trkA and trkC double labeling of DRG neurons cultured in the absence of neurotrophins on $F N(A, B, E$, $F)$ and $L M(C, D, G, H)$. At stage $23(A-D)$, most neurotrophin-independent neurites express trkC only. trkC + neurites extend equally well on LM and FN. trkA-expressing neurites (arrowheads) are few and prefer LM over FN (see Table 3). At stage $30(E-H)$, there are more trkA + neurites (arrowheads), and more neurites extend out on LM than on FN. Stage 30 neurites show a strong preference for LM (see Table 3). Arrowheads indicate neurites expressing both trkA and trkC.

teins (de Curtis, 1991; Reichardt and Tomaselli, 1991; Letourneau et al., 1994; Clegg, 2000). We characterized the expression of three laminin receptors $(\alpha 1 \beta 1, \alpha 6 \beta 1$, and $\alpha 7 \beta 1)$, one lamininfibronectin receptor $(\alpha 3 \beta 1)$, and two fibronectin receptors ( $\alpha 4 \beta 1$ and $\alpha 5 \beta 1$ ) in cultured DRGs by semiquantitative reverse transcription-PCR (Table 4). In stage 23 DRGs, all of the laminin and fibronectin receptors examined were expressed (Table 4), consistent with the efficient growth of presumptive proprioceptive neurons on both fibronectin and laminin (Fig. 5). Moreover, neither NGF or NT3 treatment altered the pattern of integrin mRNA expression, suggesting that neurotrophins neither induce nor suppress integrin expression.

In contrast to stage 23 , cultures at stage 30 had much higher levels of fibronectin receptors (integrins $\alpha 3, \alpha 4$, and $\alpha 5$ ) and lower levels of the laminin receptors integrin $\alpha 6$ and $\alpha 7$ when treated with NT3 (Table 4). These results are consistent with the
NT3-mediated survival of neurons that have superior outgrowth on fibronectin and slightly less robust growth on laminin relative to NGF-responsive neurons (Fig. 3). Differences between neurotrophin-treated cultures at stage 30 reflect the contributions of NGF-dependent (primarily cutaneous) and NT3dependent (primarily proprioceptive) neurons against a constant "background" of neurotrophin-independent non-neuronal cells (a notable percentage of cells in ganglia at this stage). This comparison indicates that there are significant differences between NGF- and NT3-responsive neurons in the levels of all integrins examined, with the exception of integrin $\alpha 1$ (Table 4 ). In agreement with the PCR analysis, antibody staining showed higher levels of integrins $\alpha 3$ and $\alpha 5$ expression in NT3-treated cultures, whereas $\alpha 1$ expression was similar between NGF- and NT3treated cells (Fig. 8A).

To ensure that neurotrophin treatment does not alter relative integrin levels, we directly compared integrin message levels from cultures without neurotrophin treatment at stage 23 and stage 30 (Fig. 8B). Laminin receptors $\alpha 1, \alpha 6$, and $\alpha 7$ are expressed at lower levels in young ganglia, whereas fibronectin receptors $\alpha 3$, $\alpha 4$, and $\alpha 5$ are expressed at much higher levels in young ganglia. The relative levels of integrins expressed in cultures without neurotrophin treatment at stage 23 versus stage 30 are very similar to the relative levels observed in NT3 versus NGF selected cultures at stage 30 (Table 4), suggesting that neurotrophin treatment does not induce integrin expression and that the changing contribution of non-neuronal cells to ganglia at different stages does not skew the analysis. These data indicate that, although integrins are expressed at both stages of development by neurons with different prospective fates, the relative amounts of particular integrins are correlated with the presumptive fate of the neurons and with their ability to interact efficiently with fibronectin. Thus, differences in integrin expression are detected before target innervation and are the earliest described prospective markers for sensory neuron fate.

We further examined the expression of integrins that showed either differential expression or approximately equivalent expression between stages 23 and 30 by in situ hybridization (Fig. 9). Consistent with the PCR analysis (Table 4, Fig. 8 ), integrin $\alpha 6$ message is distributed evenly across the DRG at both stage 23 and 30, indicating that both dorsal and ventral neurons express this integrin. In contrast, integrin $\alpha 4$ message is distributed predominantly in the ventral third of the DRG, in which the majority of proprioceptive neurons are located, and integrin $\alpha 7$ is predominantly in the dorsal half, consistent with the PCR analysis (Table 4, Fig. 8) and with the outgrowth of proprioceptive and cutaneous neurons (Figs. 3, 5). These data indicate that integrins are differentially expressed by sensory neurons with different presumptive sensory modalities before target innervation.

Table 3. Only trkA-expressing neurites prefer laminin at stage 23, whereas all stage 30 neurites prefer laminin

\begin{tabular}{|c|c|c|c|c|c|c|}
\hline \multirow[b]{2}{*}{ Stage } & \multirow[b]{2}{*}{$n$} & \multicolumn{2}{|c|}{ Total neurites } & \multicolumn{3}{|l|}{ Neurites on laminin } \\
\hline & & $\operatorname{trkA}+(\%)$ & $\operatorname{trkC}+(\%)$ & $\begin{array}{l}\text { Neurites on LM } \\
\text { (\% total neurites) }\end{array}$ & $\begin{array}{l}\text { trkA+ } \\
(\% \text { total trkA+) }\end{array}$ & $\begin{array}{l}\operatorname{trkC}+ \\
(\% \text { total trkC }+ \text { ) }\end{array}$ \\
\hline 23 & 2339 & $127(5 \%)$ & $2212(95 \%)$ & $1273(54 \%)$ & $87^{*}(70 \%)$ & $1186(54 \%)$ \\
\hline 30 & 1600 & $397(25 \%)$ & $1203(75 \%)$ & $1109(70 \%)$ & $330^{* *}(83 \%)$ & $779 *(65 \%)$ \\
\hline
\end{tabular}

DRGs were cultured $24 \mathrm{hr}$ in the absence of exogenous neurotrophins and double stained for trkA and trkC. Neurites were scored if the growth cones were more than two cell diameters beyond the limit of non-neuronal cells and therefore likely to be interacting with the substratum. Consistent with recent work (Rifkin et al., 2000), all neurites expressing trkA coexpressed trkC, with the exception of 12 stage 23 neurites from one experiment that expressed only trkA (9\% of all trkA-expressing neurites at stage 23). Neurites listed as trkC + expressed trkC only. The total number of trkA + and trkC + neurites observed on laminin are given, along with the percentage of this number represents of all neurites at this stage and the percentage of all neurites expressing trkA or trkC at this stage. Combined data from three independent experiments are shown.

${ }^{*} p<0.05$ indicates significantly different from number of neurites expressing the same trk on fibronectin at this stage ( $t$ test).

${ }^{* *} p<0.01$ indicates significantly different from number of neurites expressing the same trk on fibronectin at this stage ( $t$ test). 
Table 4. Relative integrin mRNA levels

\begin{tabular}{llllll}
\hline & \multicolumn{2}{l}{ Stage 23 } & & & \multicolumn{2}{l}{ Stage 30 } \\
\cline { 2 - 3 } \cline { 5 - 6 } Integrin & NT3 & NGF & & NT3 & NGF \\
\hline$\alpha 1$ & $0.8(0.9-0.74)$ & $1.0(1.04-0.89)$ & & $0.9(1.04-0.77)$ & $1.1(1.1-1.01)$ \\
$\alpha 3$ & $1.2(1.28-1.12)$ & $1.0(1.09-0.99)$ & & $7.0(11.13-4.37)^{*}$ & $1.7(1.86-1.53)$ \\
$\alpha 4$ & $0.9(1.22-0.71)$ & $1.0(1.17-0.94)$ & & $2.0(2.15-1.93)^{* *}$ & $0.5(0.66-0.42)$ \\
$\alpha 5$ & $1.0(1.15-0.90)$ & $0.9(1.05-0.85)$ & & $3.6(3.97-3.19)^{* *}$ & $1.6(1.75-1.42)$ \\
$\alpha 6$ & $1.0(1.24-0.89)$ & $1.0(1.13-0.88)$ & & $0.8(0.91-0.72)^{*}$ & $1.2(1.22-1.09)$ \\
$\alpha 7$ & $1.1(1.44-0.81)$ & $2.0(2.29-1.82)$ & & $0.6(0.65-0.56)^{* *}$ & $1.3(1.35-1.24)$ \\
\hline
\end{tabular}

PCR amplifications were normalized to internal (GAPDH) controls. Average percentage of control (no added neurotrophin condition) are given for NT3- and NGF-treated cultures, with upper and lower 95\% confidence limits. Data from at least three independent experiments are shown. At stage $23, \mathrm{NT} 3$ and NGF conditions were not statistically different from each other or from controls (cultures without neurotrophins). ${ }^{*} p<0.05$ indicates statistically different from NGF condition at the same stage ( $t$ test). ${ }^{* *} p<0.01$ indicates statistically different from NGF condition at the same stage $(t$ test $)$

\section{Discussion}

We showed that different prospective classes of sensory neurons have distinct behaviors and patterns of gene expression before target innervation; neurites extending before stage 25 and

A.
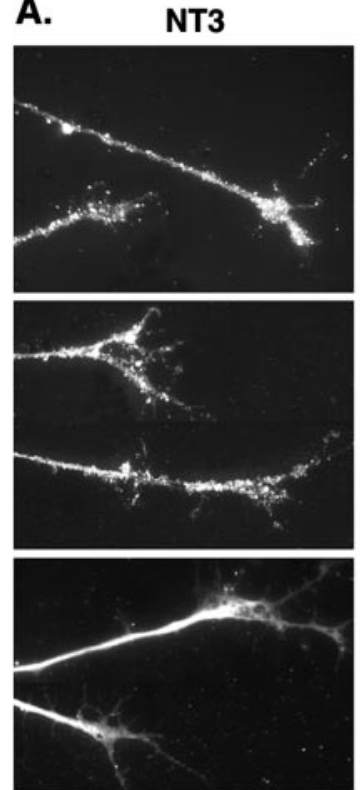

B.

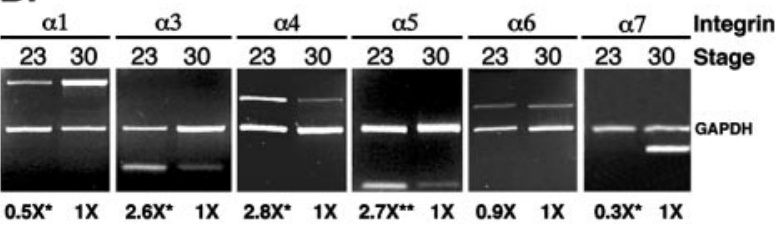

Figure 8. Differences in integrin expression are seen between different classes of sensory neurons. A, Stage 30 neurons cultured in the presence of NGF or NT3 and stained for integrin $\alpha 1 \beta 1, \alpha 3 \beta 1$, and $\alpha 5 \beta 1$. NT3- and NGF-responsive neurons in culture express similar levels of the laminin receptor integrin $\alpha 1$. In contrast, NT3-responsive neurons express much higher levels of the fibronectin receptors integrin $\alpha 3$ and $\alpha$ 5. DRGs stained for $\alpha 1$ and $\alpha 3$ were cultured on laminin, and those stained for $\alpha 5 \beta 1$ were cultured on fibronectin. Exposure for $\alpha 3-$ NGF is twice as long as exposure for $\alpha 3-$ NT3 attributable to very weak staining of NGF cultures. All other exposures are identical across the two conditions. $B, P C R$ analysis of integrin mRNA levels from stage 23 and 30 cultured without neurotrophins. Integrins $\alpha 1, \alpha 3, \alpha 4, \alpha 5, \alpha 6$, and $\alpha 7$ are expressed at both stages. Integrins $\alpha 3, \alpha 4$, and $\alpha 5$ are expressed at higher levels in stage 23 DRGs, whereas $\alpha 1$ and $\alpha 7$ levels are significantly lower at this stage. Average relative levels (normalized to stage 30 ) of amplified integrin mRNA from at least three independent experiments are given below the lanes. The $95 \%$ confidence intervals for stage 23 ratios are as follows: $\alpha 1,0.7-0.4 ; \alpha 3,3.4-2.0 ; \alpha 4,4.5-1.7 ; \alpha 5,3.2-2.0 ; \alpha 6,0.9-0.8$; and $\alpha 7$, $0.4-0.2 .^{*} p<0.05$ indicates significantly different from 1 ( $t$ test) ${ }^{* *} p<0.01$ indicates significantly different from 1 ( $t$ test).

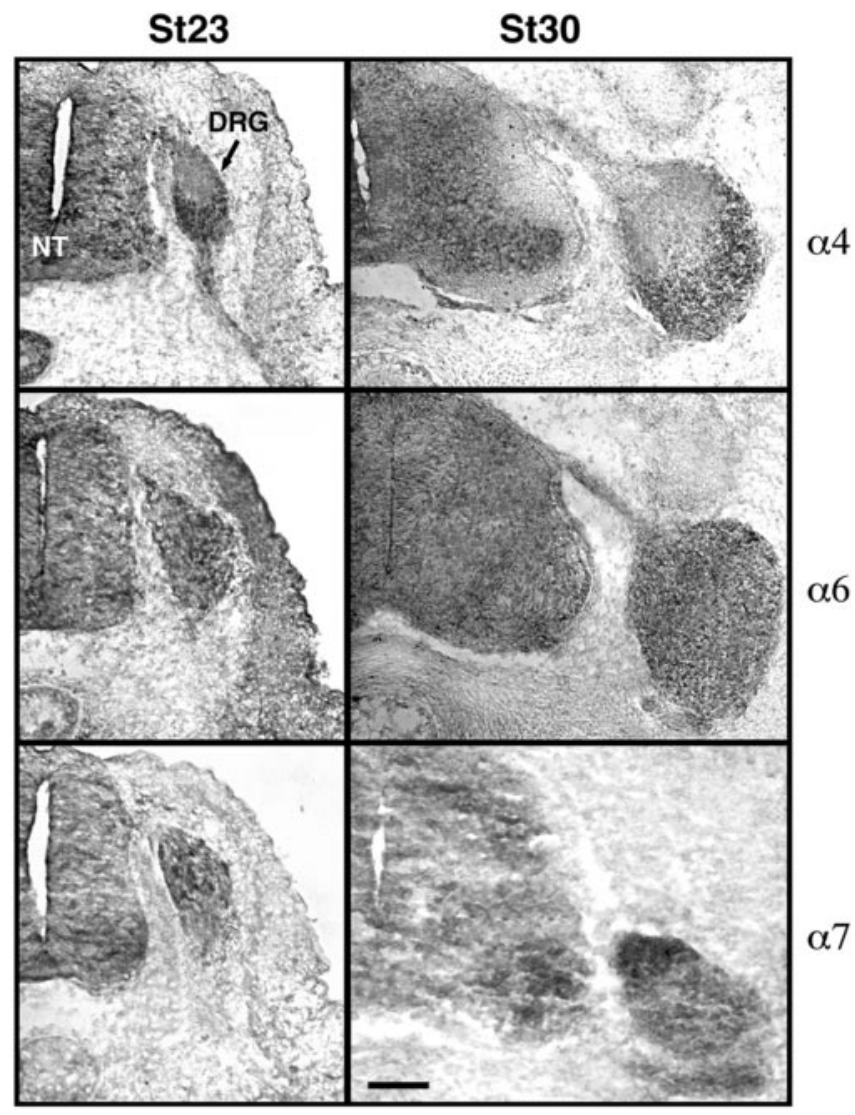

Figure 9. In situ hybridization for integrins $\alpha 4, \alpha 6$, and $\alpha 7$ at stage 23 and stage 30 . Integrin $\alpha 4$ message is localized to the ventral third of the DRG at both stages, whereas integrin $\alpha 6$ is more evenly distributed in cells scattered throughout the DRG. Integrin $\alpha 7$ is expressed in only a few cells at stage 23 and is localized predominantly dorsally by stage 30 , consistent with the PCR analysis of mRNA expression (Table 4, Fig. 8). Dorsal is up, and medial to the left. NT, Neural tube. Scale bar, $100 \mu \mathrm{m}$.

neurotrophin-independent neurites at later stages show distinct patterns of growth on laminin and fibronectin that approximately predict their ultimate fates. The differences we observed do not require exposure to targets or treatment with neurotrophins and thus are likely to reflect differences in cell specification that exist at early stages of development. Moreover, differences in growth cone extension are correlated with differences in expression of integrins, suggesting that these receptors are early markers of cell fate in DRG neurons. These results indicate that prospective classes of sensory neurons are distinguishable early in development before axon extension and that sensory neuron fate is initially specified by factors other than target-derived neurotrophins.

\section{Substratum preferences of different neuronal subclasses}

Laminin and fibronectin are prominent components of the early pathways of both proprioceptive and cutaneous afferents (Rogers et al., 1986, 1989; Lentz et al., 1997; Villanova et al., 1997). However, there are differences in the environments through which axons of different sensory subtypes extend. Early arising neurons initially path find through the fibronectin-rich matrix, whereas later arising axons fasciculate with preexisting axons on this early portion of their pathway (Fig. 2), consistent with their inability to interact with fibronectin in vitro. Thus, the choice of a growth cone to fasciculate with other axons may reflect a balance between the expression of cell adhesion molecules that facilitate 
axon-axon interactions (Rutishauser, 1985; Honig and Rutishauser, 1996; Honig et al., 1998b) and the inherent ability of a growth cone to interact with alternative, non-neuronal substrata.

Historically, integrin ligands such as laminin and fibronectin have been thought to be too broadly distributed to play a role in axon guidance (Reichardt and Tomaselli, 1991). However, recent work has shown that isoforms of laminin with distinct growthpromoting or growth-inhibiting properties have complex distributions in development (Lentz et al., 1997; Libby et al., 2000). Different laminin isoforms may be specifically recognized by particular integrins (Colognato and Yurchenco, 2000). Spatially localized distributions of laminin isoforms that are recognized by specific integrins expressed in subpopulations of neurons opens the possibility that laminin-integrin interactions may contribute to sensory neuron guidance and target selection. For example, laminins expressed in skin are predominantly laminin 1 (Lentz et al., 1997), laminin 5, laminin 6, and laminin 10/11 (Aumailley and Rousselle, 1999). Integrin $\alpha 7 \beta 1$ exists in two extracellular splice variants (X1 and X2) with different specificities for laminin isoforms (Ziober et al., 1997; Schober et al., 2000; von der Mark et al., 2002), and the restricted expression of integrin $\alpha 7 \beta 1$ to late arising cutaneous neurons could suggest different roles for this receptor, depending on which splice variant is expressed. The $\alpha 7 \mathrm{X} 2$ variant preferentially recognizes skin-associated laminins that promote efficient neurite outgrowth (Schober et al., 2000; von der Mark et al., 2002), suggesting a role in target innervation. Alternatively, the $\alpha 7 \mathrm{X} 2$ form interacts with laminin 10/11 (von der Mark et al., 2002), a "stop" signal for motor axons (Porter et al., 1995; Patton et al., 1997), suggesting a role in growth cone arrest at the target.

\section{Specification of sensory neurons}

The factors controlling sensory neuron specification are not well understood (Anderson, 1999). Previous work (see Introduction) has suggested that sensory neurons are either not specified until quite late in development or that they can be readily respecified by unknown factors present in later stage embryos. However, the directed outgrowth of axons to their targets and the nonrandom distribution of cell types within the DRG strongly suggest prespecification. Indeed, in sensory neurogenic placodes, cell fates appear to be specified before axon extension (Baker and BronnerFraser, 2000). Selective cell death can match sensory innervation to the size of the target field (Deshmukh and Johnson, 1997; Francis and Landis, 1999), but it cannot account for the directed outgrowth of sensory neurons in the first place.

In this context, it is important to distinguish between plasticity with respect to cell fate and the lack of specification. Based on the definitions of Slack (1991), the ability of a cell to adopt a novel fate indicates that it has not yet been committed to a particular phenotype. Therefore, experimental alterations in sensory neuron fates indicate that, at the time of the manipulation, neurons had not yet been committed to a particular fate but do not reveal whether the neurons have been instructed to assume a particular phenotype in normal, unmanipulated embryos (i.e., whether they have been specified).

Evidence presented here indicates that sensory neurons have unique properties before target innervation and, therefore, that the fates of sensory neurons must initially be specified by factors that are not derived from target tissues. This finding is consistent with the results of other groups indicating that neurotrophin exposure alone cannot account for specification of sensory neurons (Krimm et al., 2000; Oakley et al., 2000), yet expands on these findings by showing differences that are prospective rather than simply a failure to reassign phenotype dependent on neurotrophin treatment. Early specification may be required to ensure the proper proportions of sensory afferents are generated, whereas plasticity and/or trophic selection secondarily adjust for peripheral field size. Although target-derived factors (including neurotrophins) are capable of overriding early specification under some experimental situations, in normal development, such factors are likely to serve a supporting role by reinforcing and bringing to completion the patterns of differentiation commenced at an earlier stage.

On the basis of the evidence presented here, trk expression cannot be taken as a reliable prospective marker for DRG neuron fate. As a class, neurons initiating axons at stage 30 show a preference for laminin, regardless of their trk expression pattern, suggesting that growth on laminin is a better predictor of prospective fate at this stage than trk expression.

\section{The role of neurotrophins in neurite extension}

Several lines of evidence suggest that neurotrophins can induce specific patterns of axon extension and/or arborization. Both trigeminal (Ulupinar et al., 2000) and cortical (Castellani and Bolz, 1999) neurons exhibit distinct patterns of growth on laminin in the presence of different neurotrophins; NGF treatment results in long, unbranched neurites, whereas NT3 results in shorter, more arborized growth. These findings are consistent with the observation that neurotrophins (in this case, NT3) can directly promote neuronal branching (Gallo and Letourneau, 2000).

The current data suggest that neurotrophins also select for subpopulations of cells with different inherent properties. It is experimentally difficult to distinguish between the effects of neurotrophins on cell survival and direct effects on axon outgrowth. For example, DRGs extend neurites on cryostat sections of peripheral nervous system tissue only in the presence of NGF (Tuttle and Matthew, 1995), suggesting that either NGF induces a unique pattern of growth or NGF-dependent neurons have unique growth properties. The specific contribution of neurotrophins to axon outgrowth has been investigated using a model system that decouples cell death from neurotrophin treatment. Genetic deletion of the apoptotic mediator Bax renders neurons "death resistant," with only $40 \%$ loss of cultured Bax-/- DRG neurons after $3 \mathrm{~d}$ in the absence of neurotrophins compared with $100 \%$ loss of wild-type neurons (Lentz et al., 1999). In contrast to our current results (Figs. 5, 7, Table 3), Bax-/- neurons extend very poorly on laminin in the absence of neurotrophins (Lentz et al., 1999), suggesting that there are significant differences between the outgrowth of Bax-null mouse neurons and neurotrophin-independent wild-type chick neurons. Nonetheless, Bax-null DRG neurons also show shorter and more arborized morphologies on laminin when cultured in the presence of NT3, suggesting that NT3 acts on a broad range of neuronal subtypes to promote neurite branching and possibly to slow the neurite elongation.

The current results extend the previous work in this area by demonstrating that early sensory neurons have distinct growth patterns on different matrix molecules in the absence of neurotrophin treatment and before target innervation. The strong preference of presumptive cutaneous DRG neurons for laminin is also exhibited by sympathetic neurons that respond to both NGF and NT3, further supporting the conclusion that the ability to interact with particular ECM molecules is not dependent on neurotrophin exposure at the time of culture. These results strongly suggest that growth on laminin is an inherent property of most DRG neurons, whereas the ability to interact with fibronectin is 
primarily restricted to presumptive proprioceptive neurons. The characteristic morphologies observed in neurotrophin-selected DRG cultures are likely to reflect both the intrinsic growth properties of neuronal subpopulations and neurotrophin-induced arborization patterns.

In summary, the data presented here indicate that subpopulations of embryonic sensory neurons are distinguishable early in development. Different presumptive classes of sensory neurons have significant differences in their ability to interact with matrix proteins that arise shortly after the neurons are generated and appear to be attributable to differences in expression of integrins. These observations significantly restrict the possible mechanisms of sensory neuron specification and may provide some insight into how different subclasses of neurons navigate correctly to their targets.

\section{References}

Adams DH, Scott SA (1998) Response of "naive" cutaneous and muscle afferents to potential targets in vitro. Dev Biol 203:210-220.

Anderson DJ (1999) Lineages and transcription factors in the specification of vertebrate primary sensory neurons. Curr Opin Neurobiol 9:517-524.

Aumailley M, Rousselle P (1999) Laminins of the dermo-epidermal junction. Matrix Biol 18:19-28.

Backstrom A, Soderstrom S, Kylberg A, Ebendal T (1996) Molecular cloning of the chicken trkA and its expression in early peripheral ganglia. J Neurosci Res 46:67-81.

Baker CV, Bronner-Fraser M (2000) Establishing neuronal identity in vertebrate neurogenic placodes. Development 127:3045-3056.

Carr VM, Simpson Jr SB (1978) Proliferative and degenerative events in the early development of chick dorsal root ganglia. I. Normal development. J Comp Neurol 182:727-739.

Castellani V, Bolz J (1999) Opposing roles for neurotrophin-3 in targeting and collateral formation of distinct sets of developing cortical neurons. Development 126:3335-3345.

Clegg DO (2000) Novel roles for integrins in the nervous system 3:1-7.

Colognato H, Yurchenco PD (2000) Form and function: the laminin family of heterotrimers. Dev Dyn 218:213-234.

Davies AM (1994) The role of neurotrophins in the developing nervous system. J Neurobiol 25:1334-1348.

Davies AM (1998) Developmental changes in the neurotrophic factor survival requirements of peripheral nervous system neurons. Prog Brain Res 117:47-56.

de Curtis I (1991) Neuronal interactions with the extracellular matrix. Curr Opin Cell Biol 3:824-831.

Dechant G, Rodriguez-Tebar A, Kolbeck R, Barde YA (1993) Specific highaffinity receptors for neurotrophin-3 on sympathetic neurons. J Neurosci 13:2610-2616.

Deshmukh M, Johnson Jr EM (1997) Programmed cell death in neurons: focus on the pathway of nerve growth factor deprivation-induced death of sympathetic neurons. Mol Pharmacol 51:897-906.

Dugaiczyk A, Haron JA, Stone EM, Dennison OE, Rothblum KN, Schwartz RJ (1983) Cloning and sequencing of a deoxyribonucleic acid copy of glyceraldehyde-3-phosphate dehydrogenase messenger ribonucleic acid isolated from chicken muscle. Biochemistry 22:1605-1613.

Edlund T, Jessell TM (1999) Progression from extrinsic to intrinsic signaling in cell fate specification: a view from the nervous system. Cell 96:211-224.

Farinas I, Yoshida CK, Backus C, Reichardt LF (1996) Lack of neurotrophin-3 results in death of spinal sensory neurons and premature differentiation of their precursors. Neuron 17:1065-1078.

Ferns MJ, Hollyday M (1995) Chick wing innervation. III. Formation of axon collaterals in developing peripheral nerves. J Comp Neurol 357:272-280.

Francis NJ, Landis SC (1999) Cellular and molecular determinants of sympathetic neuron development. Annu Rev Neurosci 22:541-566.

Gallo G, Letourneau PC (2000) Neurotrophins and the dynamic regulation of the neuronal cytoskeleton. J Neurobiol 44:159-173.

Gallo G, Lefcort FB, Letourneau PC (1997) The trkA receptor mediates growth cone turning toward a localized source of nerve growth factor. J Neurosci 17:5445-5454.
Hallbook F, Backstrom A, Kullander K, Kylberg A, Williams R, Ebendal T (1995) Neurotrophins and their receptors in chicken neuronal development. Int J Dev Biol 39:855-868.

Hamburger V, Hamilton H (1951) A series of normal stages in the development of chick embryo. J Morphol 88:49-92.

Henrique D, Adam J, Myat A, Chitnis A, Lewis J, Ish-Horowicz D (1995) Expression of a Delta homologue in prospective neurons in the chick. Nature 375:787-790.

Hollyday M (1990) Specificity of initial axonal projections to embryonic chick wing. J Comp Neurol 302:589-602.

Hollyday M (1995) Chick wing innervation. I. Time course of innervation and early differentiation of the peripheral nerve pattern. J Comp Neurol 357:242-253.

Hollyday M, Morgan-Carr M (1995) Chick wing innervation. II. Morphology of motor and sensory axons and their growth cones during early development. J Comp Neurol 357:254-271.

Holst VA, Lefcort F, Rohrer H (1997) TrkA expression levels of sympathetic neurons correlate with NGF-dependent survival during development and after treatment with retinoic acid. Eur J Neurosci 9:2169-2177.

Honig MG (1982) The development of sensory projection patterns in embryonic chick hind limb. J Physiol (Lond) 330:175-202.

Honig MG, Kueter J (1995) The expression of cell adhesion molecules on the growth cones of chick cutaneous and muscle sensory neurons. Dev Biol 167:563-583.

Honig MG, Rutishauser US (1996) Changes in the segmental pattern of sensory neuron projections in the chick hindlimb under conditions of altered cell adhesion molecule function. Dev Biol 175:325-337.

Honig MG, Frase PA, Camilli SJ (1998a) The spatial relationships among cutaneous, muscle sensory and motoneuron axons during development of the chick hindlimb. Development 125:995-1004.

Honig MG, Petersen GG, Rutishauser US, Camilli SJ (1998b) In vitro studies of growth cone behavior support a role for fasciculation mediated by cell adhesion molecules in sensory axon guidance during development. Dev Biol 204:317-326.

Hunt SP, Mantyh PW, Priestley JV (1992) The organization of biochemically characterized sensory neurons. In: Sensory neurons: diversity, development, and plasticity (Scott SA, ed), pp 60-76. New York: Oxford UP.

Hynes RO, Marcantonio EE, Stepp MA, Urry LA, Yee GH (1989) Integrin heterodimer and receptor complexity in avian and mammalian cells. J Cell Biol 109:409-420.

Kahane N, Kalcheim C (1994) Expression of trkC receptor mRNA during development of the avian nervous system. J Neurobiol 25:571-584.

Kil SH, Krull CE, Cann G, Clegg D, Bronner-Fraser M (1998) The $\alpha_{4}$ subunit of integrin is important for neural crest migration. Dev Biol 202:29-42.

Krimm RF, Davis BM, Albers KM (2000) Cutaneous overexpression of neurotrophin-3 (NT3) selectively restores sensory innervation in NT3 gene knockout mice. J Neurobiol 43:40-49.

Landmesser L, Honig MG (1986) Altered sensory projections in the chick hind limb following the early removal of motoneurons. Dev Biol 118:511-531.

Lawson SN (1992) Morphological and biochemical cell types of sensory neurons. In: Sensory neurons: diversity, development, and plasticity (Scott SA, ed), pp 27-59. New York: Oxford UP.

Lawson SN, Biscoe TJ (1979) Development of mouse dorsal root ganglia: an autoradiographic and quantitative study. J Neurocytol 8:265-274.

Lawson SN, Caddy KW, Biscoe TJ (1974) Development of rat dorsal root ganglion neurones. Studies of cell birthdays and changes in mean cell diameter. Cell Tissue Res 153:399-413.

Lentz SI, Miner JH, Sanes JR, Snider WD (1997) Distribution of the ten known laminin chains in the pathways and targets of developing sensory axons. J Comp Neurol 378:547-561.

Lentz SI, Knudson CM, Korsmeyer SJ, Snider WD (1999) Neurotrophins support the development of diverse sensory axon morphologies. J Neurosci 19:1038-1048.

Letourneau PC, Condic ML, Snow DM (1994) Interactions of developing neurons with the extracellular matrix. J Neurosci 14:915-928.

Levi-Montalcini R (1987) The nerve growth factor 35 years later. Science 237:1154-1162.

Libby RT, Champliaud MF, Claudepierre T, Xu Y, Gibbons EP, Koch M, Burgeson RE, Hunter DD, Brunken WJ (2000) Laminin expression in adult and developing retinae: evidence of two novel CNS laminins. J Neurosci 20:6517-6528. 
Lin JH, Saito T, Anderson DJ, Lance-Jones C, Jessell TM, Arber S (1998) Functionally related motor neuron pool and muscle sensory afferent subtypes defined by coordinate ETS gene expression. Cell 95:393-407.

LoPresti P, Scott SA (1994) Target specificity and size of avian sensory neurons supported in vitro by nerve growth factor, brain-derived neurotrophic factor, and neurotrophin-3. J Neurobiol 25:1613-1624.

Ma Q, Fode C, Guillemot F, Anderson DJ (1999) Neurogenin 1 and neurogenin2 control two distinct waves of neurogenesis in developing dorsal root ganglia. Genes Dev 13:1717-1728.

Maisonpierre PC, Belluscio L, Conover JC, Yancopoulos GD (1992) Gene sequences of chicken BDNF and NT-3. DNA Seq 3:49-54.

Meier R, Becker-Andre M, Gotz R, Heumann R, Shaw A, Thoenen H (1986) Molecular cloning of bovine and chick nerve growth factor (NGF): delineation of conserved and unconserved domains and their relationship to the biological activity and antigenicity of NGF. EMBO J 5:1489-1493.

Mu X, Silos-Santiago I, Carroll SL, Snider WD (1993) Neurotrophin receptor genes are expressed in distinct patterns in developing dorsal root ganglia. J Neurosci 13:4029-4041.

Oakley RA, Lefcort FB, Plouffe P, Ritter A, Frank E (2000) Neurotrophin-3 promotes the survival of a limited subpopulation of cutaneous sensory neurons. Dev Biol 224:415-427.

Obata H, Hayashi K, Nishida W, Momiyama T, Uchida A, Ochi T, Sobue K (1997) Smooth muscle cell phenotype-dependent transcriptional regulation of the alphal integrin gene. J Biol Chem 272:26643-26651.

Ockel M, von Schack D, Schropel A, Dechant G, Lewin GR, Barde YA (1996) Roles of neurotrophin-3 during early development of the peripheral nervous system. Philos Trans R Soc Lond B Biol Sci 351:383-387.

Patton BL, Miner JH, Chiu AY, Sanes JR (1997) Distribution and function of laminins in the neuromuscular system of developing, adult, and mutant mice. J Cell Biol 139:1507-1521.

Pfaff S, Kintner C (1998) Neuronal diversification: development of motor neuron subtypes. Curr Opin Neurobiol 8:27-36.

Porter BE, Weis J, Sanes JR (1995) A motoneuron-selective stop signal in the synaptic protein S-laminin. Neuron 14:549-559.

Reichardt LF, Farinas I (1997) Neurotrophic factors and their receptors. In: Molecular and cellular approaches to neural development. (Cowan WM, Jessell TM, Zipursky SL, eds), pp 220-263. New York: Oxford UP.

Reichardt LF, Tomaselli TJ (1991) Extracellular matrix molecules and their receptors. Annu Rev Neurosci 14:531-570.

Rifkin JT, Todd VJ, Anderson LW, Lefcort F (2000) Dynamic expression of neurotrophin receptors during sensory neuron genesis and differentiation. Dev Biol 227:465-480.

Rogers SL, Edson KJ, Letourneau PC, McLoon SC (1986) Distribution of laminin in the developing peripheral nervous system of the chick. Dev Biol 113:429-435.

Rogers SL, Letourneau PC, Pech IV (1989) The role of fibronectin in neural development. Dev Neurosci 11:248-265.

Rutishauser U (1985) Influences of the neural cell adhesion molecule on axon growth and guidance. J Neurosci Res 13:123-131.

Schober S, Mielenz D, Echtermeyer F, Hapke S, Poschl E, von der Mark H, Moch H, von der Mark K (2000) The role of extracellular and cytoplas- mic splice domains of alpha7-integrin in cell adhesion and migration on laminins. Exp Cell Res 255:303-313.

Scott SA (1988) Skin sensory innervation patterns in embryonic chick hindlimbs deprived of motoneurons. Dev Biol 126:362-374.

Scott SA (1990) Time of origin of substance P-positive neurons in chick dorsal root ganglia. Neurosci Lett 114:135-140.

Shelton DL, Sutherland J, Gripp J, Camerato T, Armanini MP, Phillips HS, Carroll K, Spencer SD, Levinson AD (1995) Human trks: molecular cloning, tissue distribution, and expression of extracellular domain immunoadhesins. J Neurosci 15:477-491.

Shepherd IT, Luo Y, Lefcort F, Reichardt LF, Raper JA (1997) A sensory axon repellent secreted from ventral spinal cord explants is neutralized by antibodies raised against collapsin-1. Development 124:1377-1385.

Slack J (1991) Embryology. Molecule of the moment. Nature 349:17-18.

Tanabe Y, Jessell TM (1996) Diversity and pattern in the developing spinal cord. Science 274:1115-1123.

Tosney KW, Landmesser LT (1985a) Development of the major pathways for neurite outgrowth in the chick hindlimb. Dev Biol 109:193-214.

Tosney KW, Landmesser LT (1985b) Growth cone morphology and trajectory in the lumbosacral region of the chick embryo. J Neurosci 5:2345-2358

Tuttle R, Matthew WD (1995) Neurotrophins affect the pattern of DRG neurite growth in a bioassay that presents a choice of CNS and PNS substrates. Development 121:1301-1309.

Tuttle R, O'Leary DDM (1998) Neurotrophins rapidly modulate growth cone response to the axon guidance molecule, collapsin-1. Mol Cell Neurosci $11: 1-8$

Ulupinar E, Jacquin MF, Erzurumlu RS (2000) Differential effects of NGF and NT-3 on embryonic trigeminal axon growth patterns. J Comp Neurol 425:202-218.

Villanova M, Sewry C, Malandrini A, Toti P, Muntoni F, Merlini L, Torelli S, Tosi P, Maraldi NM, Guazzi GC (1997) Immunolocalization of several laminin chains in the normal human central and peripheral nervous system. J Submicrosc Cytol Pathol 29:409-413.

von der Mark H, Williams I, Wendler O, Sorokin L, von der Mark K, Poschl E (2002) Alternative splice variants of alpha 7 beta 1 integrin selectively recognize different laminin isoforms. J Biol Chem 277:6012-6016.

Wang G, Scott SA (1997) Muscle sensory innervation patterns in embryonic chick hindlimbs following dorsal root ganglion reversal. Dev Biol 186:27-35.

Wang G, Scott SA (1999) Independent development of sensory and motor innervation patterns in embryonic chick hindlimbs. Dev Biol 208:324-336.

Wang G, Scott SA (2000) The "waiting period" of sensory and motor axons in early chick hindlimb: its role in axon pathfinding and neuronal maturation. J Neurosci 20:5358-5366.

White FA, Silos-Santiago I, Molliver DC, Nishimura M, Phillips H, Barbacid M, Snider WD (1996) Synchronous onset of NGF and TrkA survival dependence in developing dorsal root ganglia. J Neurosci 16:4662-4672.

Ziober BL, Chen Y, Kramer RH (1997) The laminin-binding activity of the alpha 7 integrin receptor is defined by developmentally regulated splicing in the extracellular domain. Mol Biol Cell 8:1723-1734. 